\title{
Visual Response Properties of V1 Neurons Projecting to V2 in Macaque
}

\author{
Yasmine El-Shamayleh, Romesh D. Kumbhani, Neel T. Dhruv, and J. Anthony Movshon \\ Center for Neural Science, New York University, New York, New York 10003
}

Visual area V2 of the primate cortex receives the largest projection from area V1. V2 is thought to use its striate inputs as the basis for computations that are important for visual form processing, such as signaling angles, object borders, illusory contours, and relative binocular disparity. However, it remains unclear how selectivity for these stimulus properties emerges in V2, in part because the functional properties of the inputs are unknown. We used antidromic electrical stimulation to identify V1 neurons that project directly to V2 (10\% of all V1 neurons recorded) and characterized their electrical and visual responses. V2-projecting neurons were concentrated in the superficial and middle layers of striate cortex, consistent with the known anatomy of this cortico-cortical circuit. Most were fast conducting and temporally precise in their electrical responses, and had broad spike waveforms consistent with pyramidal regularspiking excitatory neurons. Overall, projection neurons were functionally diverse. Most, however, were tuned for orientation and binocular disparity and were strongly suppressed by large stimuli. Projection neurons included those selective and invariant to spatial phase, with roughly equal proportions. Projection neurons found in superficial layers had longer conduction times, broader spike waveforms, and were more responsive to chromatic stimuli; those found in middle layers were more strongly selective for motion direction and binocular disparity. Collectively, these response properties may be well suited for generating complex feature selectivity in and beyond V2.

\section{Introduction}

The unique neural computations that a cortical area performs reflect the functional properties of its feedforward inputs. To understand how signals are transformed by successive stages of a processing hierarchy, it is therefore important to know whether inputs to a cortical area are functionally specific or diverse. Inputs that are functionally specific may shape specialized cortical functions and confer particular properties on the target area; inputs that are functionally diverse preserve diverse stimulus information for use by subsequent stages of processing. Here, we focus on visual area V2, the second stage of visual processing in the primate cortex and assess the functional specificity of its dominant feedforward inputs from striate cortex (V1).

A gateway to the ventral visual pathway, area $\mathrm{V} 2$ is thought to have a major role in form vision. In the macaque, V2 occu-

Received June 27, 2013; revised Aug. 10, 2013; accepted Sept. 10, 2013.

Author contributions:Y.E.-S. and J.A.M. designed research;Y.E.-S., R.D.K., and N.T.D. performed research;Y.E.-S., R.D.K., and N.T.D. analyzed data; Y.E.-S., R.D.K., N.T.D., and J.A.M. wrote the paper.

This work was supported by NIH Grants EY2017 and EY4440 (J.A.M.). We thank James Cavanaugh, Peter Lennie, Christopher Tailby, and Jonathan Peirce for providing us with control V1 data. We also thank other members of the Movshon and Lennie labs for technical assistance, and Mehrdad Jazayeri for helpful discussions.

The authors declare no competing financial interests.

Correspondence should be addressed to J. Anthony Movshon, Center for Neural Science, New York University, 4 Washington Place, Room 809, New York, NY 10003. E-mail: movshon@nyu.edu.

Y. El-Shamayleh's present address: Department of Biological Structure and Washington National Primate Research Center, University of Washington, Seattle, Washington 98195.

Neel T. Dhruv's present address: UCL Institute of Ophthalmology, University College London, London EC1V 9EL, United Kingdom.

DOI:10.1523/JNEUROSCI.2753-13.2013

Copyright $\odot 2013$ the authors $\quad 0270-6474 / 13 / 3316594-12 \$ 15.00 / 0$ pies roughly one-fifth of visual cortex and about one-tenth of neocortex (Boynton and Hegdé, 2004), and is the major recipient of feedforward projections from V1. V2 responses depend on V1 input: visually evoked activity is abolished when V1 is cooled (Schiller and Malpeli, 1977; Girard and Bullier, 1989). Other V2 inputs from LGN (Bullier and Kennedy, 1983) and the pulvinar (Curcio and Harting, 1978) are known; these presumably modulate $\mathrm{V} 2$ activity without driving responses alone. Many V1 inputs converge onto V2 neurons, creating larger receptive fields. This suggests that V2 neurons combine information about simple visual elements across space, perhaps creating selectivity for complex features. Consistent with this idea, V2 neurons have been shown to be sensitive to form cues, including angles (Ito and Komatsu, 2004), shapes (Hegdé and Van Essen, 2000, 2003), object borders (Zhou et al., 2000), illusory contours (Peterhans and von der Heydt, 1989), and relative binocular disparity (Thomas et al., 2002). But we do not know how these selective responses are generated from V1 inputs.

To help uncover the visual functions of V2, we used antidromic electrical stimulation to identify $\mathrm{V} 1$ neurons projecting to V2 and characterized their visual selectivity in detail. Projection neurons had diverse response properties, but many neurons exhibited selectivity for form and binocularity, which could serve as the basis for the selective response patterns found in V2. Our findings highlight a key distinction between two major striate-extrastriate cortical projection systems: the striate projection to area MT is functionally specific (Movshon and Newsome, 1996), whereas the projection to area V2 is more functionally diverse. 


\section{Materials and Methods}

Surgical methods

We made recordings in seven male macaque monkeys (Macaca nemestrina and M. fascicularis). Animals were prepared for recording as described previously (Cavanaugh et al., 2002). Experiments typically lasted 5-6 d, during which anesthesia and paralysis were maintained with continuous intravenous infusion of sufentanil citrate (initially $6 \mu \mathrm{g} / \mathrm{kg} / \mathrm{h}$, adjusted thereafter to maintain a suitable level of anesthesia for each animal) and vecuronium bromide (Norcuron; $0.1 \mathrm{mg} / \mathrm{kg} / \mathrm{h}$ ) in isotonic dextrose-Normosol solution. Vital signs were monitored (EEG, heart rate, lung pressure, end-tidal $\mathrm{pCO}_{2}$, temperature, urine flow and specific gravity) and maintained within appropriate physiological limits. Pupils were dilated with topical atropine, and the eyes were protected with oxygen-permeable contact lenses. Supplementary lenses chosen via direct ophthalmoscopy were used to make the retinas conjugate with the experimental display. All animal care and experimental procedures were done in accordance with protocols approved by the New York University Animal Welfare Committee and conformed to the NIH Guide for Care and Use of Laboratory Animals.

\section{Electrical stimulation protocol}

We placed stimulating electrodes in cortical area V2 and recording electrodes in the retinotopically matched V1 location. The alignment of V1 and V2 receptive fields was critical for finding V1 neurons that were connected to the stimulation site, and determined the likelihood of finding projection neurons.

V2 stimulation. Low impedance $(2-20 \mathrm{k} \Omega$ ) bipolar stimulating electrodes were advanced mechanically through a craniotomy and durotomy centered 2-4 $\mathrm{mm}$ posterior to the lunate sulcus and $10 \mathrm{~mm}$ lateral to the midline. Electrode penetrations were confined to a parasagittal plane and directed downward at an angle of 0 or $20^{\circ}$ from vertical. We identified V2 by (1) marking the transition between gray and white matter as we traversed surface cortex, followed by a stretch of white matter before reaching V2 on the posterior bank of the lunate sulcus, (2) monitoring changes in visual topography along the track as we moved from surface V1 to V2, and (3) marking cortical depth along the recording track (in our experiments, V2 was typically found $2500-3500 \mu \mathrm{m}$ from brain surface). Stimulating electrodes were placed in the middle layers of V2 to target the axon terminals of $\mathrm{V} 1$ neurons projecting to the input layer, to limit the extent of electrical current spread, and to avoid the nonspecific propagation of current through fibers of passage in white matter. We mapped multiunit neuronal activity at the stimulation site, and used this to guide the placement of recording electrodes in V1. A photoisolated current source (S-910; Dagan, Cornerstone) was used to deliver electrical pulses in V2. The precise timing and parameters of stimulation events were controlled by 3 stimulator units (S-900; Dagan, Cornerstone), allowing electrical current to be delivered in several modes: monophasic or biphasic, tip positive or negative, $200-500 \mu \mathrm{s} /$ phase; $0.3-2.5 \mathrm{~mA}$. We stimulated at $11 \mathrm{~V} 2$ sites in total: one in each of four monkeys, two in each of two monkeys, and three in one monkey.

$V 1$ recordings. Single unit extracellular recordings were made using glass-coated platinum-plated tungsten microelectrodes (Merrill and Ainsworth, 1972), advanced mechanically through a separate duratomy. Electrode penetrations were confined to a parasagittal plane and directed downward at an angle of $70^{\circ}$ from vertical. In most experiments, the retinotopically matched $\mathrm{V} 1$ location was found $7-10 \mathrm{~mm}$ posterior of the stimulating electrodes; receptive fields were $2.8-5.7^{\circ}$ eccentric. Signals from the microelectrodes were amplified, bandpass filtered ( $300 \mathrm{~Hz}$ to 10 $\mathrm{kHz}$ ), and fed into a dual window time-amplitude discriminator (Bak Electronics). Spike times were saved with a temporal resolution of $0.1 \mathrm{~ms}$. Voltage traces were also saved for later reconstruction of the collision test (see Fig. 3).

\section{Experimental tactics and controls}

Because only $\sim 10 \%$ of V1 neurons were found to project to V2 using these methods, the yield for this experiment was significantly lower than in standard single-unit recording studies. To collect a reasonable sample of projection neurons while minimizing the number of monkeys used, we decided to characterize the visual response properties of V1 neurons that were electrically connected to V2 (i.e., showed antidromic or orthodromic activation) and to pass neurons by if they had no electrical connection. Following a previous study of the V1 neurons that project to cortical area MT (Movshon and Newsome, 1996) and to provide the control data needed to represent the population of unconnected neurons, we also made comparisons to larger data sets of V1 neurons that were recorded "blind," without measuring connectivity. These control data were recorded in separate experiments by our group and by colleagues in the lab of Peter Lennie at New York University; all were published previously. They were recorded in the same laboratory using the same equipment, at comparable visual eccentricities, using the same stimuli, and we analyzed the data exactly as we analyzed those from connected neurons. As far as we can determine, these data represent an unbiased sample of the general population of V1 neurons. However, we cannot completely rule out differences across experiments and experimenters that might have led to biases in the control data. Control data for orientation and direction selectivity, center size, surround suppression, and semisaturation contrast were provided by Cavanaugh et al. (2002). Control data for spatial frequency, relative modulation, binocular interaction index, and chromatic elevation were recorded by Peter Lennie and colleagues, including one author of the current study. Control data for the binocular interaction index were provided by Peirce et al. (2008). Control data for spatial frequency and relative modulation were provided by Dhruv et al. (2011). Control data for chromatic preference were provided by Tailby et al. (2008).

\section{Visual stimuli}

We presented stimuli on a gamma-corrected CRT monitor (Eizo T966; mean luminance, $33 \mathrm{~cd} / \mathrm{m}^{2}$ ) at a resolution of 1280 by 960 pixels and a refresh rate of $120 \mathrm{~Hz}$. Stimuli were generated using Expo software on an Apple Macintosh computer (https://corevision.cns.nyu.edu/expo/).

For each cell, we mapped the receptive field through each eye on a tangent screen. After determining ocular dominance, we presented subsequent stimuli monocularly through the cell's dominant eye, except for binocular experiments. We characterized neuronal selectivity for orientation and direction, spatial frequency, drift rate, and size using highcontrast sinusoidal gratings. In addition, we measured sensitivity to contrast, spatial phase, chromatic modulation, and binocular disparity.

\section{Data analysis}

To quantify neuronal selectivity, we fit suitable descriptive functions to the measured tuning curves and extracted relevant parameters and indices.

Orientation and direction selectivity indices. We quantified selectivity for grating orientation and direction with a vector-based measure of tuning strength, as detailed previously (Smith et al., 2002). We computed the summed response vector and normalized its magnitude by the summed magnitude of all response vectors. Index values range from 0 to 1 , where 1 indicates responses only to a single orientation or direction, and 0 indicates equal responses to all orientations or directions. The orientation selectivity index (OSI) is related to the "circular variance" (CV) measure of orientation bandwidth (Ringach et al., 1997): the OSI is $1-\mathrm{CV}$ computed over the range $0-180^{\circ}$. The direction selectivity index (DSI) is $1-\mathrm{CV}$ computed over the range $0-360^{\circ}$.

Surround suppression index. We quantified the degree to which responses were suppressed by stimuli larger than the classical receptive field, as detailed previously (Cavanaugh et al., 2002). We computed an index that expressed suppression as a fraction of the peak response. Index values range from 0 to 1 , where 0 indicates no suppression, and 1 indicates complete suppression.

Relative response modulation. We classified cells as simple or complex using the relative modulation index (F1/F0) (Movshon et al., 1978a,b; Skottun et al., 1991). From spatial frequency tuning curves, we computed the ratio of the first harmonic to the average firing rate (F1/F0). Cells with a ratio $\geq 1$ showed strong response modulation and were classified as simple; those with a ratio $\leq 1$ showed a large F0 component and were classified as complex. We computed an analogous quantity from the spatial phase tuning experiments (see Fig. 7A, inset) by fitting a cycle of a sine wave to the responses and calculating 
the ratio of the fit amplitude to its offset. Both measures resulted in similar classification of cells.

Binocular interaction index. We measured responses to variations in the relative interocular spatial phase of drifting sinusoidal gratings presented through each eye. We quantified the strength of disparity tuning by computing a binocular interaction index (BII), as detailed previously (Ohzawa and Freeman, 1986). We fit a cycle of a sine wave to the binocular responses (see Fig. 7C) and calculated the ratio of the fit amplitude to its offset. A value of 0 indicated no response modulation (flat tuning); a value of 1 indicated complete response suppression $180^{\circ}$ away from the optimal spatial phase. Following previously published criteria, cells with a BII of $\geq 0.3$ were classified as having significant phase-specific binocular interactions.

Chromatic selectivity. We measured responses to a family of gratings that sampled color space systematically, as described previously (Derrington et al., 1984; Lennie et al., 1990). We presented stimuli along three planes in that space (see Fig. $8 \mathrm{C}$ ): modulations confined to the isoluminant plane, and modulations along either the constant $\mathrm{B}$ axis ( $\mathrm{L}-\mathrm{M}$ cone modulation) or the constant $\mathrm{R}-\mathrm{G}$ axis ( $\mathrm{S}$ cone modulation) with simultaneous increments or decrements of luminance modulation. A cell's chromatic selectivity was defined by fitting a linear model to its joint responses along the three planes, as described previously (Derrington et al., 1984; Lennie et al., 1990). We extracted the cell's preferred direction in color space: a vector that is defined by the azimuthal angle in the isoluminant plane and the elevation angle from the isoluminant plane. Cells were classified based on their preferred elevation angle, following previous published criteria (Solomon and Lennie, 2005): cells with elevations $\geq 80^{\circ}$ preferred luminance modulation; those with elevations of $50-80^{\circ}$ were equally responsive to luminance and chromatic modulation; those with elevations $\leq 50^{\circ}$ preferred chromatic modulation.

Statistical comparisons of population distributions. We compared distributions of response properties across projection and coupled neurons recorded in the current study. We also compared their responses to larger data sets of V1 neurons recorded in separate experiments, without knowledge of connectivity to V2. For each distribution, we computed an appropriate measure of central tendency (arithmetic or geometric mean) and determined statistical significance using a two-tailed permutation test (bootstrap procedure). Briefly, we dissociated the data from their labels and drew random samples of size equal to the observed groups, without replacement, and computed the probability that the observed difference could have occurred by chance. The number of iterations $(N=$ 2000) was sufficient to derive an estimate of the underlying $p$ value that was within a standard error of $10 \%$ of its actual value. To ask whether V1 neurons involved in V2 circuitry represented a specialized subset of all V1 neurons, we compared three groups of neurons (see Results; Fig. 1E). For each response property tested, we compared distributions of projection and coupled neurons (the latter were connected to V2, but not detectably through a feedforward monosynaptic connection), projection and control neurons, and coupled and control neurons. The resulting probabilities are listed in Table 1. Our criterion for significance was $p \leq 0.025$. These statistical comparisons were confirmed by secondary tests, which included a nonparametric one-way ANOVA (Kruskal-Wallis test; data not shown) applied to the same pairwise comparisons shown in Table 1 and to a multiple comparison of all neuronal groups. To further assess differences between projection and control neurons, we asked whether random sampling of control neurons could have resulted in distributions that resembled the observed projection distributions. Using a similar bootstrap procedure, and for each property tested, we drew a random simulated projection distribution from the control population of size equal to the observed projection distribution. From this, we computed the probability that the observed distribution could have occurred by chance; this analysis also confirmed the findings derived from our main statistical comparisons (Table 1). Finally, we confirmed that the observed differences between projection and coupled neurons were unaffected by the number of stimulus repeats used to characterize neuronal selectivity.

\section{Results}

We identified, by antidromic electrical stimulation, striate cortical neurons that project directly to area V2 and characterized
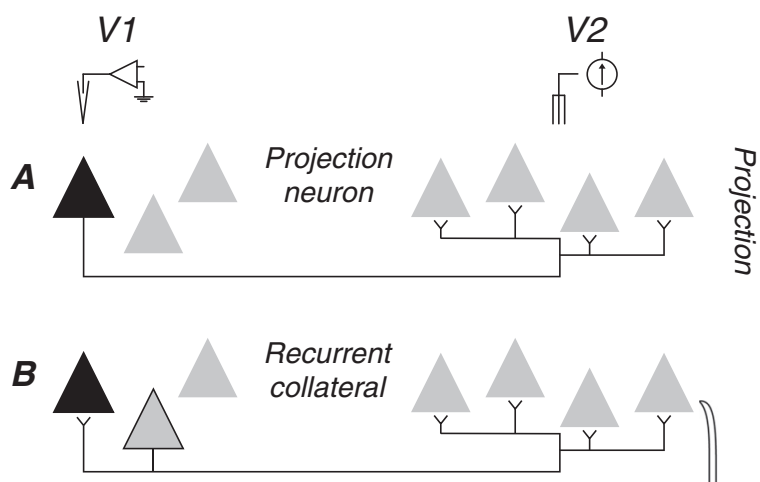

Recurrent collateral
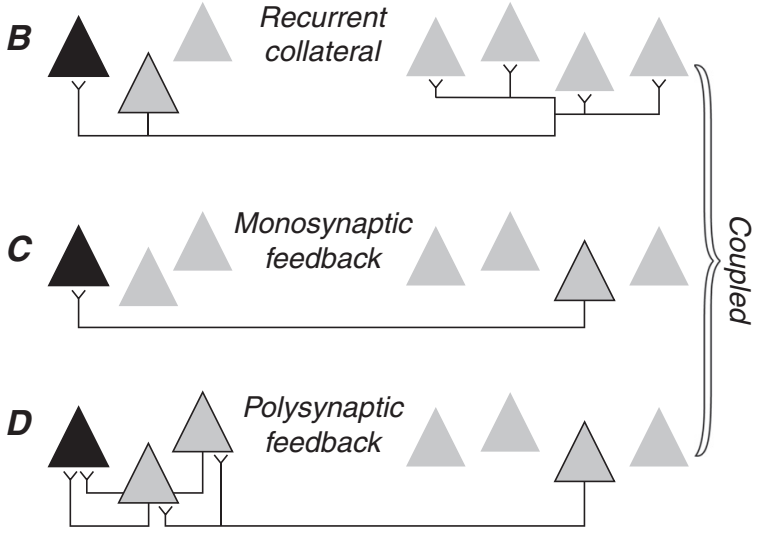

E

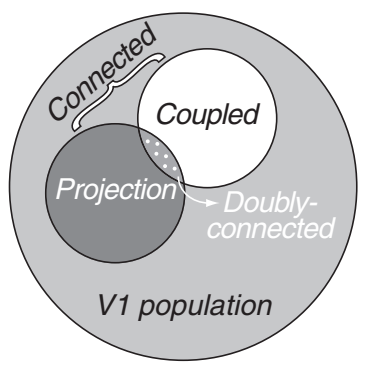

Figure 1. Possible neuronal circuits linking V1 and V2. A-D, Triangles symbolize hypothetical groups of neurons in V1 (right) and V2 (left). In each panel, black symbols represent the neuron recorded; in $\boldsymbol{B}-\boldsymbol{D}$, gray symbols with black outlines represent the neurons that relay the electrically elicited spikes. $A$, Feedforward projection: here, a spontaneous V1 spike would collide with a suitably delayed electrically elicited spike, thus satisfying the collision test. $\boldsymbol{B}-\boldsymbol{D}$, Other possible circuits in which the electrically elicited spike will not be occluded and the collision test will fail. $\boldsymbol{B}$, Recurrent collateral of a neighboring projection neuron. $\boldsymbol{C}$, Monosynaptic feedback projection. $\boldsymbol{D}$, Polysynaptic feedback connection. Because we cannot distinguish among the circuit arrangements shown in $\boldsymbol{B}-\boldsymbol{D}$, we classify all connected cells that fail the collision test as "coupled." $\boldsymbol{E}$, Schematic showing the relationship of projection and coupled neurons to the larger V1 population. Note that some neurons may be both projection and coupled.

their electrical and visual response properties. To determine connectivity, we delivered single monophasic electrical pulses in V2 and recorded evoked V1 spikes. To establish the direction of connectivity, we used the collision test (Bishop et al., 1962); V1 cells that showed occlusion of electrically elicited antidromic spikes by spontaneous orthodromic spikes were taken to be V2 projecting. The precise alignment of V1 and V2 receptive fields was critical for finding projection neurons.

\section{Circuits linking V1 and V2}

Figure $1 A-D$ caricatures some possible neuronal circuits linking areas V1 and V2. In each case, the black triangle represents a recorded V1 neuron; gray triangles represent other neurons in V1 (left) or V2 (right); symbols with black outlines represent neurons that relay the electrically evoked signal. In the case of a feedforward projection (Fig. 1A), a spontaneous spike traveling in the forward (orthodromic) direction will collide with a suit- 


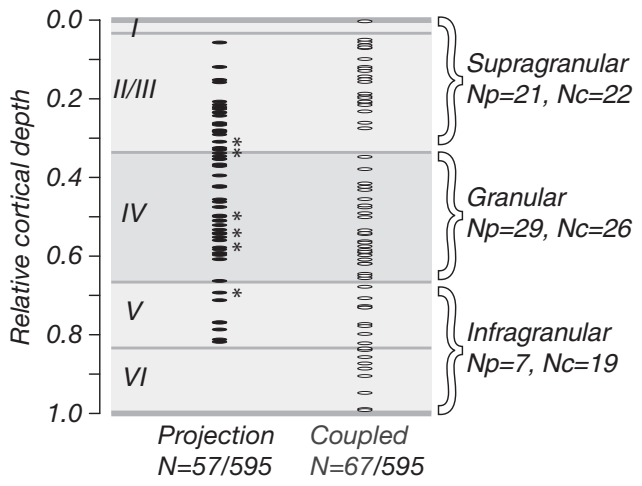

Figure 2. Location and proportion of V2-connected neurons. Relative cortical depth of projection ( $N=57$ ) and coupled $(N=67)$ neurons whose visual selectivity we characterized (595 neurons recorded in total). Depth was computed as a fraction of the distance along recording tracks (from brain surface to white matter); laminar boundaries were drawn based on measurements of macaque Nissl-stained tissue sections (Tyler et al., 1998). Projection neurons ( $\sim 10 \%$ of all neurons recorded) were concentrated in cortical layers $2 / 3$ and 4 ; coupled neurons were found in all layers. Asterisks show the locations of six doubly connected neurons; these were concentrated in the middle layers. Numbers of projection and coupled neurons in different laminar compartments (supragranular, granular, and infragranular) are listed (right; $N p$ and $N c$, respectively).

ably delayed electrically elicited spike traveling in the backward (antidromic) direction. The delay required for collision is taken as a measure of neuronal conduction time. Figure $1 B-D$ shows several circuits for which the collision test will fail; electrically elicited spikes will not be occluded because they reach the recorded neuron through a synaptic connection. These include the recurrent collateral of a neighboring projection neuron (Fig. $1 B$ ), as well as monosynaptic and polysynaptic feedback connections (Fig. 1C,D). Our measurements do not distinguish these circuit arrangements, so we classified all cells that failed the collision test as "coupled," without implying any particular V1-V2 circuit relationship. Figure $1 E$ shows that neurons connected to V2-both projection and coupled (dark gray and white) - are subsets of the larger V1 population (light gray). Note that a V1 neuron can be both projection and coupled by having multiple connection patterns with V2, hence the overlapping subsets in Figure $1 E$ (dotted region). We refer to these neurons as "doubly connected." In this study, we asked whether the projection neurons constitute a functionally specialized subpopulation, with visual response properties that differ from other V1 neurons.

\section{Location and proportion of $\mathrm{V} 2$-connected neurons}

We searched for V2-connected neurons in all layers of striate cortex. We recorded 595 neurons in seven macaque monkeys and stimulated at $11 \mathrm{~V} 2$ sites in total. Of these neurons, $162(27 \%)$ were electrically connected to V2; $59(10 \%)$ were classified as "projection" neurons by the collision test; 103 (17\%) were classified as "coupled" neurons. We characterized the visual selectivity of 57 projection neurons and 67 coupled neurons; data from these neurons are the basis for this study. Figure 2 shows the relative cortical depth of our recordings, shown separately for projection and coupled neurons. Cortical depths were computed as a fraction of the distance along recording tracks; layer borders were drawn based on previously published measurements of Nissl-stained macaque V1 tissue (Tyler et al., 1998). V1 neurons projecting to $\mathrm{V} 2$ were concentrated in the superficial and middle layers of striate cortex, consistent with anatomical studies show- ing that $\mathrm{V} 2$ receives most of its feedforward striate input from layers 2/3 and 4B (Lund et al., 1981; Van Essen et al., 1986; Rockland, 1992; Nassi and Callaway, 2007). In contrast, coupled neurons were found in all layers of V1, consistent with a more diffuse pattern of feedback and recurrent connections across cortical lamina.

We also examined the proportions of projection and coupled neurons across different laminar compartments (right), dividing total cortical depth into thirds (supragranular, granular, and infragranular). Note that this analysis is intended to assess general trends of the functional properties of neurons across cortical depth. The compartment labels used here are simply intended to reflect the relative grouping of data into subsets from superficial, middle, and deep layers of striate cortex. Neurons of both types were equally prevalent in the supragranular and granular compartments, but projection neurons were relatively rare in the infragranular compartment. The six doubly connected neurons we recorded (Fig. 2, asterisks) were all in the granular compartment or close to its borders ( $<30 \mu \mathrm{m}$ away).

\section{Electrical properties}

Figure $3 A-D$ shows collision test records for four V1 neurons. Each panel shows $\sim 20$ superimposed voltage traces aligned to the onset of the electrical stimuli (indicated by triangles), triggered after the occurrence of a spontaneous spike in the V1 cell. We repeated the collision tests at three delays (indicated by the time of the spontaneous spikes preceding electrical stimulation, open circles): longer, near, and shorter than the electrical conduction time (Fig. $3 A-D$, top, middle, and bottom subpanels, respectively). Figure $3 A$ shows the results for a projection neuron. At the two longest delays, we recorded spikes in the interval following stimulation (filled circles); these had short latency, no failures, and minimal jitter. At the shortest delay, however, electrically elicited spikes were occluded by the preceding spontaneous orthodromic spikes. This neuron therefore passed the collision test and was classified as a projection neuron. Figure $3 B$ shows the results for a coupled neuron, which failed the collision test; in the interval following stimulation, we recorded spikes at all collision delays. Poststimulation spikes had a high degree of temporal jitter, characteristic of synaptic conduction, and the probabilistic nature of neurotransmission. Some V1 neurons have more than one V1-V2 connection, and can be both projection and coupled. Figure $3 C$ shows such a cell, doubly connected to V2, showing signatures of both antidromic and orthodromic activation. At the two longest delays, the neuron exhibited two modes of firing: one that occurred at a short electrical latency with minimal jitter and another at a longer latency with high temporal jitter. At the shortest stimulation delay, the short latency spike was almost completely occluded, whereas the long latency spike survived and became more reliable, presumably because it was no longer affected by the relative refractory period following the antidromic spike. This activation pattern is consistent with the neuron having an axonal projection to $\mathrm{V} 2$, in addition to another connection through which V2 signals reach V1 (presumably one or more of the motifs in Fig. $1 B-D$ ). Figure 3D shows the results for another doubly connected neuron. In this case, orthodromic activation was only visible at the shortest delay when the antidromic spike was occluded, presumably because the synaptically driven spike otherwise fell within the absolute refractory period after the antidromic spike. For the main purposes of this study, doubly connected neurons $(N=6$; Fig. 2) were classified as projection neurons; their response properties did not differ from other projection neurons in any other regard. 


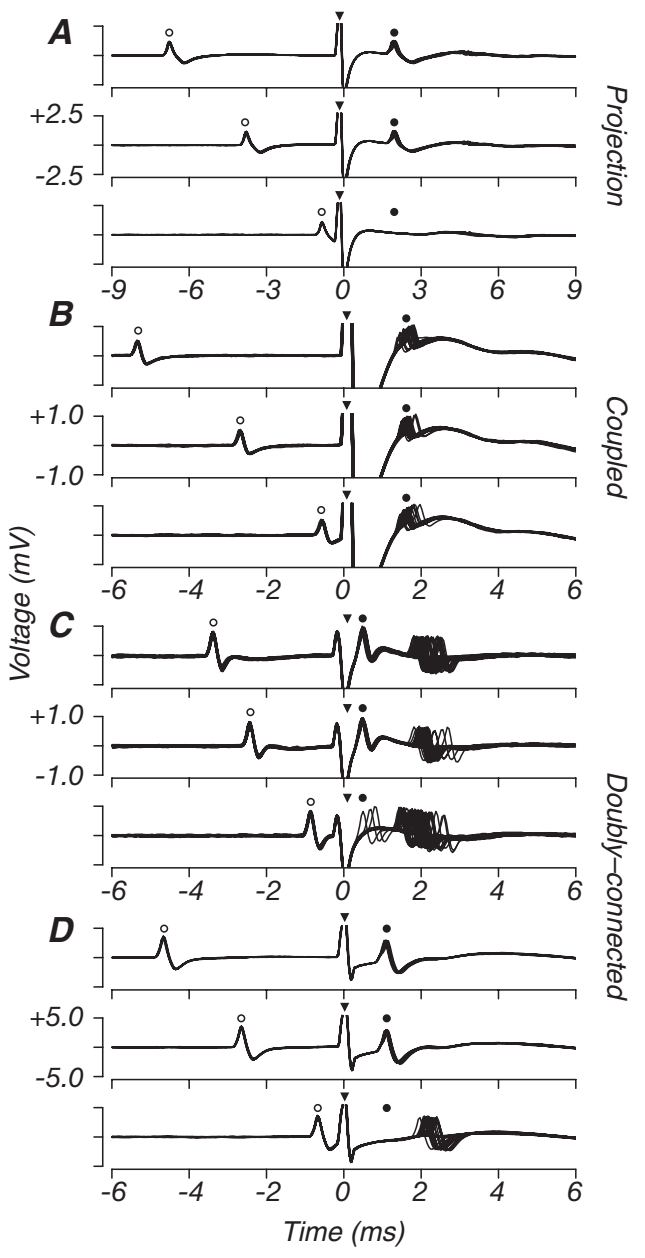

Figure 3. Example collision tests. Each panel shows $\sim 20$ superimposed voltage traces aligned to the onset of the electrical stimulation artifact ( $0 \mathrm{~ms}$, filled triangles), and extending $6-9 \mathrm{~ms}$ before and after the artifact. Stimulation was triggered on the occurrence of a spontaneous V1 spike (open circles). $\boldsymbol{A}-\boldsymbol{D}$, For each neuron tested, we performed the collision test at three delays: longer, near, and shorter than the conduction time (top, middle, bottom, respectively). $A$, Results for a projection neuron that passed the collision test. At the long and medium delays, electrically elicited spikes (filled circles) were visible in the poststimulation epoch; these had short latency and minimal temporal jitter. At the shortest delay, these spikes were completely occluded by the spontaneous spike. $\boldsymbol{B}$, Results for a coupled neuron that failed the collision test. Electrically elicited spikes were visible at all collision delays, without occlusion. $\boldsymbol{C}$, Results for a doubly connected neuron that showed two modes of activation: one at short latency (antidromic, <1ms) and with minimal jitter, the other at longer latency (orthodromic, $\sim 2 \mathrm{~ms}$ ) and with high jitter. At the shortest delay, only the short latency spike was occluded. This pattern is consistent with the neuron having a V2-projecting axon as well as another "coupled" connection. D, Results for another doubly connected neuron; here, orthodromic activation was only visible at the shortest delay when the electrically elicited spike was fully occluded. In this study, doubly connected neurons were classified as projection neurons.

We took electrical latency as the time from the onset of the electrical stimulus artifact to the foot of the electrically elicited V1 spike; this was equivalent to the neuron's conduction time. We also measured latency jitter as the SD of conduction times. Figure $4 A$ shows measurements of electrical latency versus jitter for all $117 \mathrm{~V} 1$ neurons for which these data were preserved (for the other 45 neurons, measurements sufficient to classify cells were done, but repeated trials were not recorded). While the distributions overlapped, projection neurons (black circles, $N=50$ ) had shorter conduction times and lower temporal jitter than coupled neurons (white circles, $N=67$ ). Mean latencies for projection and coupled neurons were 1.67 and $2.97 \mathrm{~ms}$, respectively; mean jitter was 0.07 and $0.27 \mathrm{~ms}$, respectively (triangles). Mean latency

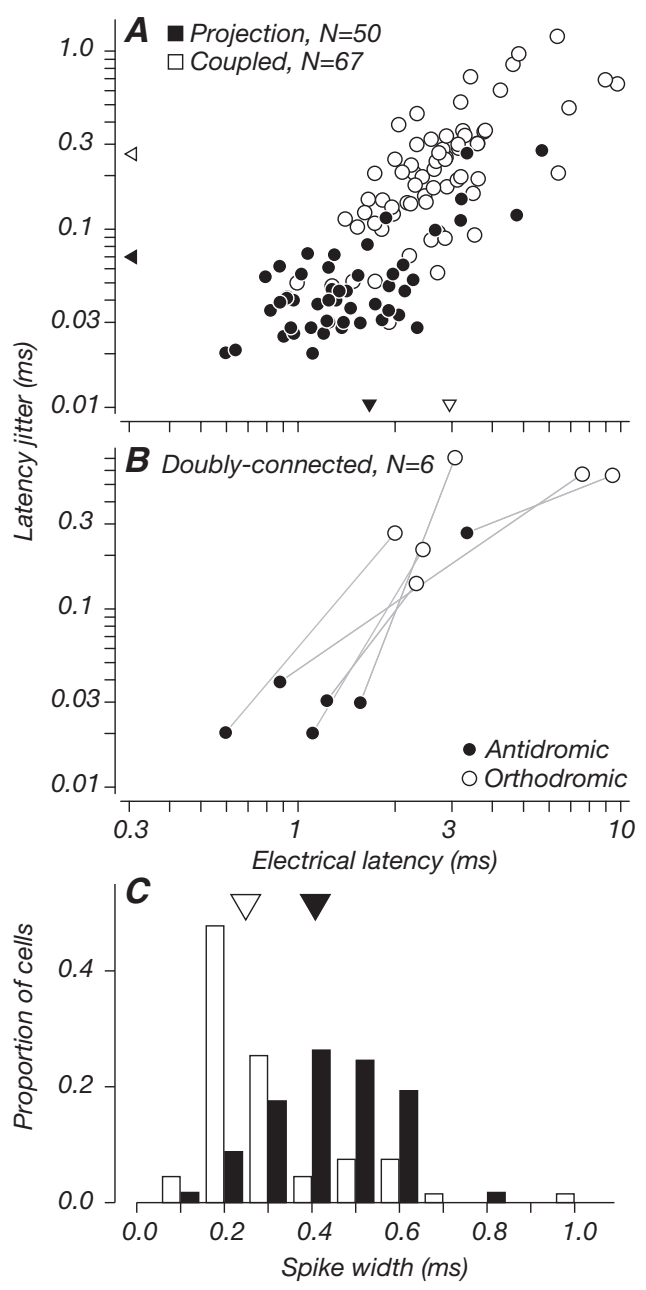

Figure 4. Electrical latency, latency jitter, and spike width. Latency was measured as the average time from the foot of the electrical artifact to the foot of the poststimulus spike. Jitter was measured as the SD of poststimulus spike latencies. $A$, Electrical latency versus jitter for all connected neurons for which we saved collision test data $(N=117)$. On average, projection neurons (black) had shorter electrical latencies (mean, $1.67 \mathrm{~ms}$; triangles) than coupled neurons (white, $2.97 \mathrm{~ms}$ ); projection neurons also had less jitter (mean, $0.07 \mathrm{~ms}$ ) than coupled neurons $(0.27 \mathrm{~ms})$. Both differences were significant $(p<0.001)$. B , Same measurements for doubly connected cells $(N=6$; as in Fig. $2 C, D)$. Values are shown separately for antidromic and orthodromic spikes. In the same neurons, latency and jitter were considerably lower for antidromic spikes compared to orthodromic spikes. Note that in $\boldsymbol{A}$, we include the data for the antidromic spikes of doubly connected cells, but not their orthodromic spikes. C, Distributions of spike width, measured as the time from largest trough to the largest peak of the spike waveform. Projection neurons had broader spike waveforms (mean, $0.43 \mathrm{~ms}$ ) than coupled neurons (mean, $0.31 \mathrm{~ms}$ ), consistent with the notion that most projection neurons are regular-spiking excitatory neurons. Coupled neurons with very narrow spike waveforms ( $\sim 0.20 \mathrm{~ms})$ may be fast-spiking inhibitory interneurons. The difference between the distribution means was statistically significant $(p<0.001)$.

and jitter differences between groups were statistically significant $(p<0.001)$. We examined these differences across cortical depth, repeating our analyses separately for neurons recorded in the supragranular and granular compartments (Fig. 2). We did not compare neurons recorded in the infragranular compartment where projection neurons were only rarely found because our statistical comparisons would not have sufficient power. Differences in latency and jitter between projection and coupled neurons were statistically significant in both compartments $(p \leq 0.001)$. Neurons recorded in superficial layers had longer latencies compared to those in middle layers $(p \leq 0.001)$ : mean latencies for projection neurons were 2.22 and $1.16 \mathrm{~ms}$, respec- 
tively; mean latencies for coupled neurons were and 3.93 and 2.36 ms. Two projection neurons had electrical latencies shorter than $0.7 \mathrm{~ms}$. Because the typical refractory period for cortical cells is $\sim 1 \mathrm{~ms}$, we cannot be certain that the occlusion of antidromic spikes at the shortest collision test delays in these two cases was not simply due to refractoriness. Figure $4 B$ shows the analogous plot for six doubly-connected cells; here, we measured latency and jitter separately for antidromic and orthodromic spikes. When compared in the same neurons, antidromically activated spikes had shorter latencies and lower jitter than orthodromically activated spikes. These results are consistent with previous measurements of the electrical properties of $\mathrm{V} 1$ neurons projecting to V2 (Girard et al., 2001); feedforward projections tend to have faster conduction velocities and higher temporal precision than other V1-V2 circuits. However, we do not identify orthodromic (synaptic) activation in coupled neurons as "feedback" for the reasons given previously and illustrated in Figure $1 B-D$.

From records of the collision test, we also extracted measurements of the extracellular waveform duration in the epoch before electrical stimulation. We measured spike width as the time from the largest trough to the largest peak of the average waveform, as in previous studies (Mitchell et al., 2007; Hussar and Pasternak, 2009). Figure $4 C$ shows the distribution of spike width for projection and coupled neurons. Projection neurons had broader spike waveforms than coupled neurons, on average (means, 0.43 and $0.31 \mathrm{~ms})$; this difference was statistically significant $(p<$ 0.001 ). The relatively broad spike waveforms of projection neurons are consistent with the idea that these are often regularspiking excitatory neurons with pyramidal morphology (McCormick et al., 1985). The subset of coupled neurons with very narrow spike waveforms $(\sim 0.20 \mathrm{~ms})$ might suggest that they are fast-spiking inhibitory neurons with stellate morphology (McCormick et al., 1985; but see Vigneswaran et al., 2011). Differences between the distributions of projection and coupled neurons held across the supragranular and granular compartments $(p<0.001$ and $p<0.025)$. Interestingly, the mean spike width for projection neurons recorded in the superficial layers was longer than in the middle layers $(0.49$ and $0.39 \mathrm{~ms} ; p=$ $0.008) ; 76 \%$ of neurons in superficial layers had spike widths $\geq 0.4 \mathrm{~ms}$ (the population average of all projection neurons), whereas only $38 \%$ of those in middle layers met that criterion. This difference across compartments may reflect the fact that at least some of the projection neurons from layer $4 \mathrm{~B}$ are known to have stellate morphology (Nassi and Callaway, 2007).

\section{Visual response properties}

To assess the functional specificity of projection neurons, we examined their visual selectivity in detail. We compared the response properties of projection neurons to those of coupled neurons and to larger data sets of V1 neurons recorded without knowledge of connectivity to V2 at comparable receptive field eccentricities (for more details on these control data, see Materials and Methods, Experimental tactics and controls). We performed three pairwise statistical comparisons of population distributions (Fig. 1E, Table 1): (1) projection and coupled; (2) projection and control; (3) coupled and control. We place more emphasis on comparisons between projection and coupled neurons because these were recorded in the same experiments. In addition, while coupled neurons failed the collision test, they were still involved in the V1-V2 circuit, whereas the larger control data sets presumably contained cells associated with other brain areas.

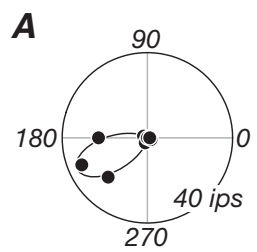

\section{B}
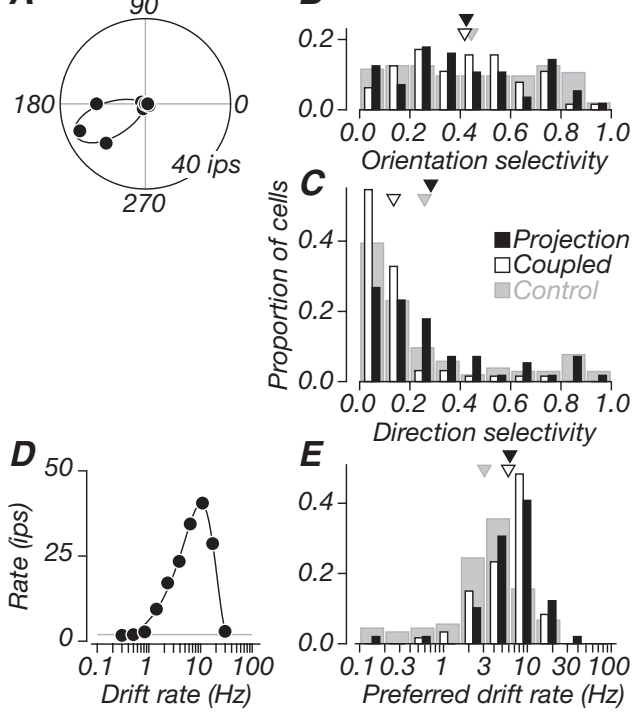

Figure 5. Direction and speed. $\boldsymbol{A}$, Direction tuning of an example projection neuron in polar coordinates. The black line is a model fit to the data (von Mises); baseline firing is plotted but unobservable ( $\sim 0$ impulses per second). The neuron was selective for grating orientation (OSI, 0.77) and direction (DSI, 0.86). B, Population distributions of OSIs. Projection neurons (black) were usually selective for grating orientation; they were, on average, as selective as coupled (white) and control (gray) neurons. C, Population distributions of DSIs. Projection neurons were on average weakly direction selective, and not different from controls. However, both projection and control neurons were significantly more direction selective than coupled neurons. $\boldsymbol{D}$, Tuning for drift rate. The black line is a model fit to the data (difference of Gaussians); the gray line indicates baseline firing. The neuron was bandpass, with a preferred rate of $10 \mathrm{~Hz}$. $\boldsymbol{E}$, Population distributions of preferred drift rate. Projection and coupled neurons preferred similar drift rates, and both groups preferred higher drift rates than controls. Triangles in $\boldsymbol{B}, \boldsymbol{D}$, and $\boldsymbol{E}$ indicate population means.

In the following figures (Figs. 5-8), and for each response property tested, we show data from a single example projection neuron (the same throughout) and population distributions of relevant tuning parameters across all cortical lamina. We also highlight interesting differences in the properties of neurons across cortical depth throughout the text.

\section{Direction and speed}

Figure $5 \mathrm{~A}$ shows the direction tuning of an example projection neuron to drifting gratings; it was selective for both orientation and direction, as captured by orientation and direction selectivity indices (OSI, 0.77; DSI, 0.86; see Materials and Methods). Figure $5, B$ and $C$, shows distributions of these selectivity indices for the three groups of V1 neurons: projection (black), coupled (white), and control (gray). Projection neurons were, on average, well tuned for grating orientation (Fig. 5B; triangles indicate mean values); the distributions of orientation selectivity indices for all groups had similar means. Overall, neurons in all groups showed more prominent orientation selectivity than direction selectivity (Fig. 5C). However, there were important differences in the direction selectivity of neuronal groups. Projection neurons were, on average, more direction selective than coupled neurons $(p<$ $0.001)$; this difference held across the supragranular and granular compartments ( $p=0.004$ and $p=0.001$ ). While projection neurons were not different from controls, coupled neurons were less direction selective than controls $(p<0.001)$. Projection neurons in middle layers were, on average, more direction selective than in superficial layers (mean DSIs, 0.37 and 0.20 ); $28 \%$ of neurons 


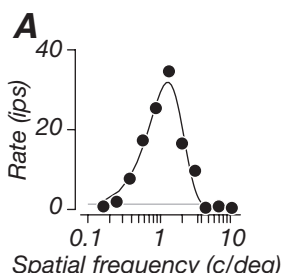

Spatial frequency (c/deg)
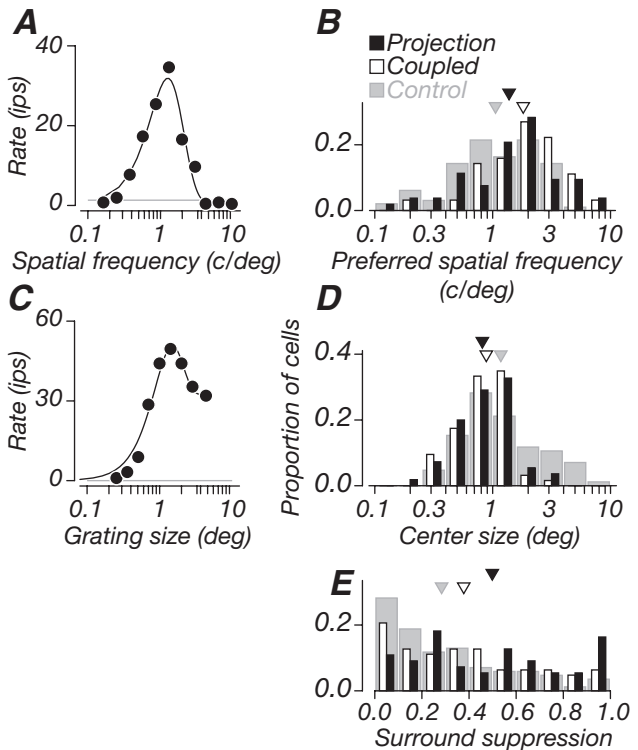

Figure 6. Spatial properties. $\boldsymbol{A}$, Spatial frequency tuning of a projection neuron (same as in previous figures). The black line is a model fit to the data (difference of Gaussians). The neuron was bandpass, with a preferred spatial frequency of 1.3 cycles/degree. $\boldsymbol{B}$, Population distributions of preferred spatial frequency: projection, coupled, and control neurons preferred similar frequencies on average. C, Tuning for grating patch size. The black line is a model fit to the data (integral of difference of Gaussians). The neuron was moderately suppressed by stimuli that entered the receptive field surround; optimal grating size (center size) was $1.3^{\circ} ; \mathrm{SSI}$ was 0.36 . Gray lines in $\boldsymbol{A}$ and $\boldsymbol{C}$ indicate baseline firing. $\boldsymbol{D}$, Population distributions of center size: projection and coupled neurons had similar sizes on average, and both were significantly smaller than controls. $\boldsymbol{E}$, Population distributions of SSI: projection neurons showed stronger suppression than either coupled or control neurons; coupled neurons also showed stronger suppression than controls. Triangles in $\boldsymbol{B}, \boldsymbol{D}$, and $\boldsymbol{E}$ indicate population means.

in middle layers had a DSI $\geq 0.5$, whereas only $5 \%$ of neurons in superficial layers met this criterion.

Figure $5 D$ shows the neuron's tuning for the speed of moving gratings (drift rate); it was bandpass, with a preferred drift rate of $10 \mathrm{~Hz}$. Population distributions of preferred drift rate are shown in Figure 5E. Projection and coupled neurons preferred similar drift rates on average; both groups preferred higher drift rates than control neurons $(p<0.001)$. These data show that V2 receives both orientation and direction information from $\mathrm{V} 1$; this functional diversity is consistent with V2's role in both the dorsal and ventral streams of visual processing.

\section{Spatial properties}

Figure $6 A$ shows the same example neuron's tuning for spatial frequency, which was bandpass, with a preferred frequency of 1.3 cycles/degree. Population distributions of preferred spatial frequency are shown in Figure 6B. Projection and coupled neurons preferred similar frequencies on average, as did projection and control neurons. Coupled neurons preferred higher spatial frequencies than controls $(p<0.001)$.

Figure $6 C$ shows the example neuron's tuning for grating patch size; it was moderately suppressed by stimuli larger than the classical receptive field. From these responses, we extracted optimal grating size, which captures the spatial extent of the receptive field center, and surround suppression index (SSI), which expresses suppression as a fraction of the peak response (Cavanaugh et al., 2002). For this neuron, optimal size was $1.3^{\circ}$, and the SSI was 0.36 . Population distributions of center size and SSI are shown in Figure 6, D and E. Projection and coupled neurons had similar center receptive field sizes on average, but both were significantly smaller than controls $(p=0.001, p=0.006)$. On average, projection neurons were more strongly suppressed than the coupled and control neurons $(p=0.015, p<0.001)$. Coupled neurons also showed stronger suppression than controls ( $p=$ $0.025)$. The magnitude of surround suppression was in fact the only visual response property that distinguished projection neurons from both other groups of V1 neurons, suggesting that the $\mathrm{V} 1-\mathrm{V} 2$ projection is specific in this regard: V2 preferentially receives input from strongly surround-suppressed V1 neurons. We examined differences in the magnitude of surround suppression between projection and coupled neurons across cortical depth; these were statistically significant for neurons in the granular compartment ( $p=0.005)$. This was mainly due to weaker surround suppression in coupled neurons in middle layers compared to those in superficial layers; only $25 \%$ of coupled neurons in middle layers had an SSI $\geq 0.5$, whereas $47 \%$ of those recorded in superficial layers met this criterion.

\section{Monocular and binocular phase}

We measured responses to flashed static gratings at different spatial phases, presented monocularly to the dominant eye. Figure $7 A$ shows responses of the example neuron, which were weakly sensitive to variations of spatial phase. We quantified the strength of modulation by fitting a sinusoid to these data and computing the amplitude-to-offset ratio (ratio, 0.24). For consistency with previous studies, we also computed relative modulation (F1/F0; Movshon et al., 1978a,b; Skottun et al., 1991) from the cycleaverage response measured at the optimal spatial frequency in a separate experiment (Fig. 7A, inset; see Materials and Methods; F1/F0, 0.51). For this neuron and all others, both methods gave

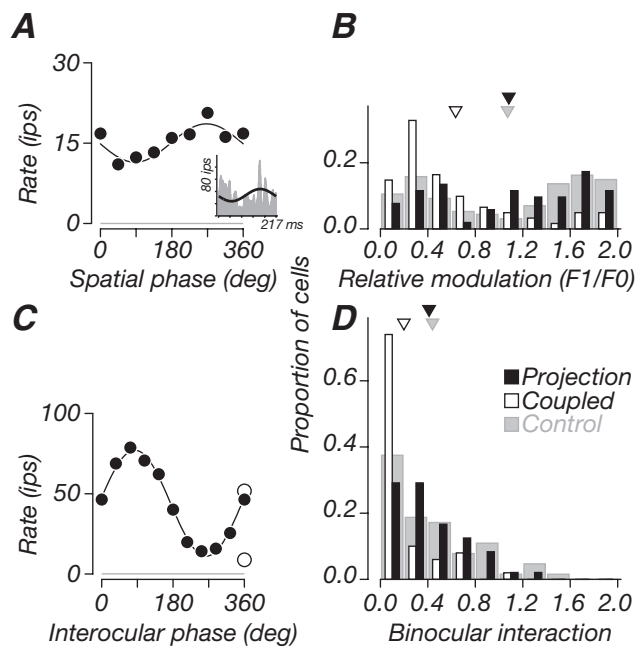

Figure 7. Monocular and binocular phase. $\boldsymbol{A}$, Tuning of a projection neuron (same as in previous figures) for the spatial phase of monocularly presented flashed gratings. The black line is a sinusoidal fit to the responses. The neuron showed weak modulation (amplitude to offset ratio, 0.24$)$. Inset, Cycle-average response measured at the optimal spatial frequency in a separate experiment (F1/F0, 0.51). $\boldsymbol{B}$, Population distributions of relative response modulation ratio. Projection neurons could be either simple or complex; their distribution was similar to that of controls, but tended more often to be simple. Thus, V2 receives strong spatial phase information. C, Tuning for relative interocular phase of drifting gratings presented binocularly (filled circles). The black line is a sinusoidal fit to the binocular responses; responses to monocular gratings are also shown (open circles). Binocular responses were strongly modulated around the monocular conditions, suggesting tuning for grating disparity; the Bll was 0.75 . Gray lines in $\boldsymbol{A}$ and $\boldsymbol{C}$ indicate baseline firing. $\boldsymbol{D}$, Population distributions of Bll. Many projection neurons (52\%) had Bll values above 0.3 (criterion for significance) and were on average more sensitive to binocular disparity than coupled neurons but as sensitive as controls. Triangles in $\boldsymbol{B}$ and $\boldsymbol{D}$ indicate population means. 
similar results; this neuron was categorized as complex. Population distributions of the relative response modulation index are shown in Figure $7 B$. Projection neurons could be either simple or complex, and tended more often to be simple compared to coupled neurons $(p<0.001)$, but did not differ from V1 controls. Coupled neurons tended more often to be complex compared to controls $(p<0.001)$. The difference between projection and coupled neurons held across both the supragranular and granular compartments $(p=0.021, p=0.014)$. In superficial layers, $56 \%$ of projection neurons were classified as simple (F1/F0, $\geq 1$, compared to only $35 \%$ of coupled neurons. In middle layers, $64 \%$ of projection neurons were simple, compared to only $20 \%$ of coupled neurons. Thus, many V1 inputs to V2 carry information about spatial phase.

Previous studies have shown that most V2 neurons are binocularly driven (Hubel and Wiesel, 1970; Roe and Ts'o, 1995), and that some are selective for forms defined by binocular disparity (von der Heydt et al., 2000; Thomas et al., 2002; Qiu and von der Heydt, 2005; Bredfeldt and Cumming, 2006). To ask how V1 inputs contribute to binocular responses in V2, we examined the strength of binocular interactions in projection neurons. Figure $7 C$ shows the example neuron's tuning for binocular disparity. Responses are shown as a function of the relative interocular spatial phase of drifting gratings presented binocularly (filled circles); monocular responses through each eye alone are plotted separately (open circles). We varied the phase of the grating in the eye that gave the weaker monocular response. Responses to binocular stimulation were strongly modulated around the monocular condition, suggesting strong binocular interaction. We quantified the strength of this interaction with the binocular interaction index (BII) (Ohzawa and Freeman, 1986; see Materials and Methods) and followed previously published criteria for classifying cells as having strong disparity tuning (BII, $\geq 0.3$; Ohzawa and Freeman, 1986). This neuron had a BII of 0.75, indicating significant binocular interaction. Population distributions of BII are shown in Figure $7 D$. On average, projection neurons exhibited stronger binocular interaction than coupled neurons $(p<$ $0.001)$. Roughly half of projection neurons (52\%) had significant binocular interactions, whereas a smaller subset of coupled neurons $(18 \%)$ passed the criterion for significance. Although projection neurons did not differ from controls (53\% of control neurons passed the criterion), coupled neurons were on average less selective for binocular disparity than controls $(p<0.001)$. Differences between projection and coupled neurons held across the supragranular and granular compartments $(p=0.025, p=$ $0.008) ; 53 \%$ of projection neurons in superficial layers, and $58 \%$ of neurons in middle layers showed significant binocular interactions. From these data, we conclude that many V2-projecting neurons were selective for binocular disparity and could contribute directly to the binocular response properties observed in V2.

There was no relationship between monocular and binocular phase sensitivity for the projection neurons; neurons with strong binocular interactions (BII, $\geq 0.3$ ) could be simple or complex, as reported previously in cats (Ohzawa and Freeman, 1986). We noticed that some projection neurons were strikingly modulated by binocular disparity, even though the monocular response in the less effective eye was weak (Fig. 7C). We captured this "binocular amplification" by computing the ratio of the amplitude of the disparity-dependent modulation to the response in the weaker eye. For projection neurons, the geometric mean of this ratio was 1.71 , while for coupled neurons it was only 0.58 ; this difference was significant $(p<0.001)$. Strong disparity-

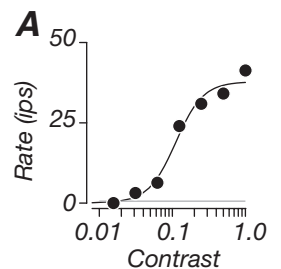

B
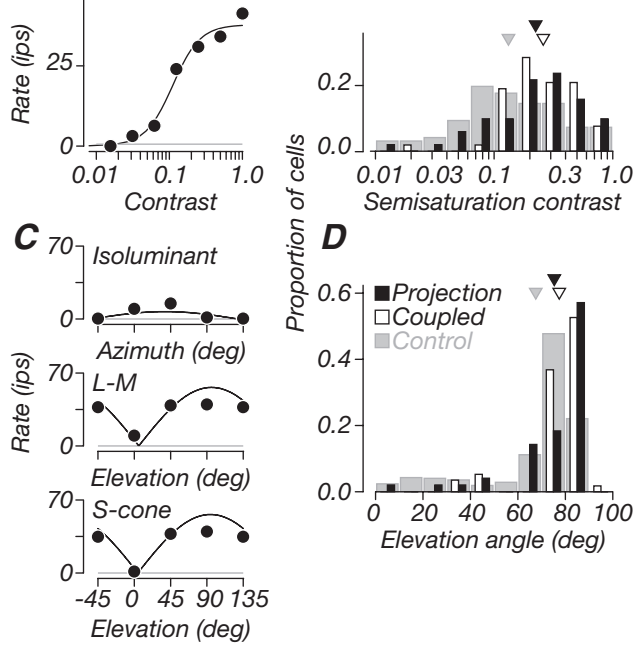

Figure 8. Contrast and color. $\boldsymbol{A}$ Contrast-response function of a projection neuron (same as in previous figures). It was moderately sensitive to luminance contrast (semisaturation contrast, 0.11). $\boldsymbol{B}$ Population distribution of semisaturation contrast. Projection neurons were on average as sensitive as coupled neurons, but both had lower contrast sensitivity than control data. $C$, Responses along three planes in the color space used in our experiments: azimuth in the isoluminant plane (top, chromatic modulation), elevation through the constant B axis (middle, $\mathrm{L}-\mathrm{M}$ cone modulation), and elevation through the constant $\mathrm{R}-\mathrm{G}$ axis (bottom, $\mathrm{S}$ cone modulation). A neuron's color selectivity was defined by fitting these responses with a linear model (black lines; see Materials and Methods) and extracting the preferred direction in color space. We used the preferred elevation to characterize cells (see Materials and Methods). The example neuron had a preferred elevation of $83^{\circ}$, and therefore preferred luminance stimuli. Gray lines in $\boldsymbol{A}$ and $\boldsymbol{C}$ indicate baseline firing. D, Population distributions of preferred elevation angles. Projection and coupled neurons tended to prefer higher elevation angles; compared to controls, most projection neurons ( $>50 \%$ ) were better driven by luminance than chromatic stimuli. Triangles in $\boldsymbol{B}$ and $\boldsymbol{D}$ indicate population means.

dependent response modulation is therefore a hallmark of the projection from $\mathrm{V} 1$ to $\mathrm{V} 2$.

\section{Sensitivity to contrast and color}

Figure $8 A$ shows the example neuron's contrast response function. It was moderately sensitive to increasing luminance contrast, with a semisaturation contrast $\left(\mathrm{C}_{50}\right)$ of 0.11 . Population distributions of semisaturation contrast are shown in Figure $8 B$. Projection and coupled neurons showed similar sensitivity to luminance contrast. Both projection and coupled neurons were less sensitive than controls $(p=0.001, p=0.002)$. On average, neurons involved in V2 circuitry appeared to have lower contrast sensitivity than the general V1 neuronal population.

We measured neuronal sensitivity to luminance and chromatic modulation. Figure $8 C$ shows the responses of the example neuron to luminance and chromatic gratings, which sampled directions in the color space used in our experiments (Derrington et al., 1984; Lennie et al., 1990; see Materials and Methods). The neuron showed weak responses to isoluminant stimuli in all color directions, but strong responses to luminance stimuli; responses were strongest at elevation angles close to $90^{\circ}$ and weakest at elevation angle $0^{\circ}$, corresponding to pure luminance and pure chromatic modulation, respectively. We quantified chromatic selectivity by fitting the responses in all planes jointly using a model based on linear combinations of cone signals (Derrington et al., 1984; Lennie et al., 1990; solid lines) and extracting the neuron's preferred azimuth and elevation angles (see Materials and Methods). Selectivity for azimuth was dispersed across the population and not different among any of our groups, so we classified cells 
Table 1. Statistical comparisons of population data

\begin{tabular}{lccc}
\hline Property & $\begin{array}{l}\text { Projection versus } \\
\text { coupled }\end{array}$ & $\begin{array}{l}\text { Projection versus } \\
\text { control }\end{array}$ & $\begin{array}{c}\text { Coupled versus } \\
\text { control }\end{array}$ \\
\hline Latency & $\begin{array}{c}<.001^{*} \\
<0.001^{*} \\
\text { Jitter }\end{array}$ & & \\
Spike width & $0.001^{*}$ & & \\
Orientation selectivity index & 0.416 & 0.359 & 0.246 \\
Direction selectivity index & $<0.001^{*}$ & 0.294 & $<0.001^{*}$ \\
Preferred drift rate & 0.391 & $<0.001^{*}$ & $<0.001^{*}$ \\
Preferred spatial frequency & 0.038 & 0.042 & $<0.001^{*}$ \\
Receptive field size & 0.200 & $0.001^{*}$ & $0.006^{*}$ \\
Surround suppression index & $0.015^{*}$ & $<0.001^{*}$ & $0.025^{*}$ \\
Relative response modulation & $<0.001^{*}$ & 0.455 & $<0.001^{*}$ \\
Binocular interaction index & $<0.001^{*}$ & 0.329 & $<0.001^{*}$ \\
Semisaturation contrast & 0.466 & $0.001^{*}$ & $0.002^{*}$ \\
Preferred elevation angle & 0.250 & $0.002^{*}$ & $<0.001^{*}$ \\
\hline
\end{tabular}

We used permutation analyses to compute the probabilities that differences in the response properties of different neuronal groups could have arisen by chance. We show pairwise statistical comparisons for distributions of projection, coupled, and control neurons. Probabilities are shown.

${ }^{*} p \leq 0.025$ (two-tailed).

by their elevation angles, according to previously published criteria (Solomon and Lennie, 2005): neurons with preferred elevations $\geq 80^{\circ}$ were luminance preferring, those with preferred elevations between $50-80^{\circ}$ were equally responsive to luminance and chromatic modulation, and those with preferred elevations $\leq 50^{\circ}$ were chromatic preferring. The example neuron had a preferred elevation of $83^{\circ}$, and thus preferred luminance stimuli. Population distributions of preferred elevation angle are shown in Figure $8 D$. Most projection neurons preferred luminance stimuli (57\%), and only a small subset (10\%) preferred chromatic stimuli. Similarly, most coupled neurons preferred luminance stimuli (54\%), and a small subset (9\%) preferred chromatic stimuli. In contrast, most control neurons $(62 \%)$ were equally responsive to luminance and chromatic stimuli, and smaller proportions of neurons preferred luminance $(22 \%)$ and chromatic (16\%) modulation. On average, the preferred elevation angles for projection and coupled neurons were not statistically different. However, projection neurons were less color-selective than controls ( $p=0.002)$, as were coupled neurons $(p<0.001)$. Thus, most neurons projecting to V2 preferred forms defined by luminance rather than color. However, when we examined the properties of neurons across cortical depth, we found that projection neurons recorded in the supragranular compartment were, on average, more responsive to color than those recorded in the granular compartment $(p<0.001)$. About $27 \%$ of projection neurons in the superficial layers were classified as chromatic preferring; none of those recorded in middle layers were classified as such. Furthermore, $47 \%$ of projection neurons in superficial layers were equally responsive to luminance and chromatic stimuli, compared to only $25 \%$ in middle layers. Thus, it appears that although striate inputs to V2 are not strongly sensitive to chromatic stimuli overall, the strongest color signals to $\mathrm{V} 2$ originate in the superficial layers of V1.

\section{Discussion}

To better understand the contribution of cortical area V2 to visual processing, we examined the response properties of its dominant feedforward inputs, assessing their functional specificity. We identified V1 neurons projecting to V2 using antidromic stimulation and measured their electrical and visual responses. Projection neurons, $\sim 10 \%$ of our recorded sample of V1 neurons, were concentrated in the superficial and middle layers of striate cortex (Fig. 2), consistent with previous anatomical stud- ies of this major cortico-cortical pathway (Lund et al., 1981; Van Essen et al., 1986; Rockland, 1992; Nassi and Callaway, 2007).

The antidromically activated spikes of projection neurons had shorter conduction times than the orthodromically activated spikes of coupled neurons (Fig. $4 A$; means were 1.7 and $3.0 \mathrm{~ms}$, respectively). However, we observed a wide range of electrical latencies: $0.6-5.7 \mathrm{~ms}$ for projection neurons and $0.9-9.8 \mathrm{~ms}$ for coupled neurons. Interestingly, neurons in middle layers had significantly shorter latencies than those in superficial layers (means were 1.2 and $2.2 \mathrm{~ms}$ for projection; 2.4 and $3.9 \mathrm{~ms}$ for coupled). Our measurements are consistent with a previous study of V1-V2 conduction times (Girard et al., 2001). While we cannot determine the particular V1-V2 circuit motifs that underlie orthodromic activation (Fig. $1 B-D$ ), our measurements show that information is transmitted rapidly between these areas, suggesting a tight functional link between neural processing in the two earliest stages of visual cortex.

Projection neurons had, on average, broader extracellular waveforms than coupled neurons (Fig. 4C; means were 0.43 and $0.31 \mathrm{~ms}$, respectively). While absolute measurements of spike width depend critically on the filter parameters, the difference between groups suggests different biophysical and morphological properties. Broad waveforms are characteristic of regularspiking excitatory pyramidal neurons, whereas narrow waveforms are characteristic of fast-spiking inhibitory interneurons (McCormick et al., 1985; Mitchell et al., 2007; Hussar and Pasternak, 2009; but for fast-spiking pyramidal cells, see Vigneswaran et al., 2011). Our findings are consistent with the notion that most V2-projecting neurons are pyramidal relay neurons, although anatomical studies have shown that some layer $4 \mathrm{~B}$ projection neurons have stellate morphology (Nassi and Callaway, 2007).

Unlike the homogeneous population of V1 neurons that project to area MT (Movshon and Newsome, 1996), V2-projecting neurons included all the main functional types of V1 neurons. The only visual response property that reliably distinguished projection neurons from both the coupled and control populations was surround suppression-projection neurons were significantly more strongly suppressed by stimuli that engaged the receptive field surround (Fig. $6 E$ ). Surround suppression mechanisms have been implicated in the generation of context-related signals in V2, such as figure-ground segregation (Zhou et al., 2000), scene segmentation (Marcus and Van Essen, 2002), and the detection of illusory contours (Peterhans and von der Heydt, 1989). These mechanisms may underlie neuronal selectivity for particular arrangements of visual features in V2, such as angles, contours, and simple forms (Hegdé and Van Essen, 2000, 2003; Ito and Komatsu, 2004; Anzai et al., 2007; El-Shamayleh and Movshon, 2011), and contribute to the emergence of complex shape selectivity in downstream areas V4 and IT (Gallant et al., 1993; Pasupathy and Connor, 2001; Brincat and Connor, 2004). Suppression within the classical receptive fields of V2 neurons has also been linked to selectivity for natural image statistics (Willmore et al., 2010). These interactions may reflect the surround suppression evident in the responses of V1 afferents, the neurons we have identified and characterized here.

Over half of the projection neurons were strongly modulated by binocular disparity (Fig. $7 D$ ), and these interactions could occur even when stimuli in the nondominant eye evoked only weak responses. These disparity signals, which were strongest in the middle layers, are a plausible foundation for the selectivity of V2 neurons for stereoscopic edges (von der Heydt et al., 2000; Qiu and von der Heydt, 2005) and relative disparity (Thomas et 
al., 2002; Tanabe and Cumming, 2008), and may contribute to the emergence of 3D shape tuning in IT cortex (Yamane et al., 2008).

Most projection neurons preferred achromatic to chromatic stimuli. A larger proportion of those in superficial layers were equally responsive to achromatic and chromatic stimuli compared to those in middle layers ( $47 \%$ and $25 \%)$. The overall paucity of color-selective neurons in our data set may have arisen from sampling biases: while we aimed to sample V1 evenly, perhaps one-fifth of cortex lies within the cytochrome oxidase (CO) "blobs" where color-selective cells are prevalent (Livingstone and Hubel, 1984). Interestingly, our measurements of color selectivity in projection neurons (Fig. $8 D$ ) were remarkably similar to analogous measurements made in V2 using the same stimuli and analyses (Solomon and Lennie, 2005, their Fig. 2). Even in V2, neurons strongly modulated by chromatic stimuli were rare; the similarity between these data sets suggests that V2 inherits its color selectivity from V1. Chromatic signals may also be relayed to extrastriate cortex through a direct and putatively specialized pathway from V1 to V4, which is confined to the central visual representation (Zeki, 1978; Yukie and Iwai, 1985).

Projection neurons included both simple and complex cells (Fig. $7 B$ ). V2 therefore receives two input streams, one selective for spatial phase information (simple) and another that is not (complex). Over half of V2-projecting neurons were simple (56\% in superficial layers and $64 \%$ in middle layers), challenging the traditional notion that V1 outputs can be adequately modeled as complex cells.

To summarize (Fig. 9), compared to a control population of V1 neurons recorded without knowledge of their projection termination patterns, V2-projecting neurons showed stronger surround suppression, smaller receptive fields, higher preferred drift rates, and lower contrast and chromatic sensitivities. The properties of coupled neurons, linked to V2 but not through a monosynaptic feedforward connection, were similarly distributed, and in addition showed less direction selectivity, weaker binocular interactions, and less response modulation than both control and projection neurons. Overall, coupled neurons showed the largest functional differences from projection and control neurons, perhaps because their signals have been transformed by extra steps of intracortical processing. Consistent with this, most coupled neurons were complex (Fig. $7 B$ ), had relatively long conduction times, and more variable spike timing (Fig. $4 A$ ).

The heterogeneity of the V1 input to V2 is to be expected-it carries signals that will ultimately be distributed to many downstream targets in both the dorsal and ventral streams of visual processing. Moreover, because visual form information can be carried by different cues, the ventral stream needs access to diverse sets of inputs to accomplish its computational goals. In contrast, striate projections to MT have more homogeneous functional properties. MT-projecting neurons are distinctively direction selective and complex (Movshon and Newsome, 1996), suggesting that the V1-MT cortical projection is specialized for relaying visual motion information. MT-projecting neurons have relatively high temporal resolution and contrast sensitivity compared to V2-projecting neurons (Fig. 5E, $8 B$ ). These differences are consistent with the idea that MT, a dorsal stream area, receives predominantly magnocellular input whereas $\mathrm{V} 2$, an area involved in both dorsal and ventral stream circuits, receives a mixture of magnocellular and parvocellular input (Maunsell et al., 1990; Ferrera et al., 1994).

Neurons in V1 and V2 have diverse response properties related to the cytochrome oxidase defined compartments in the

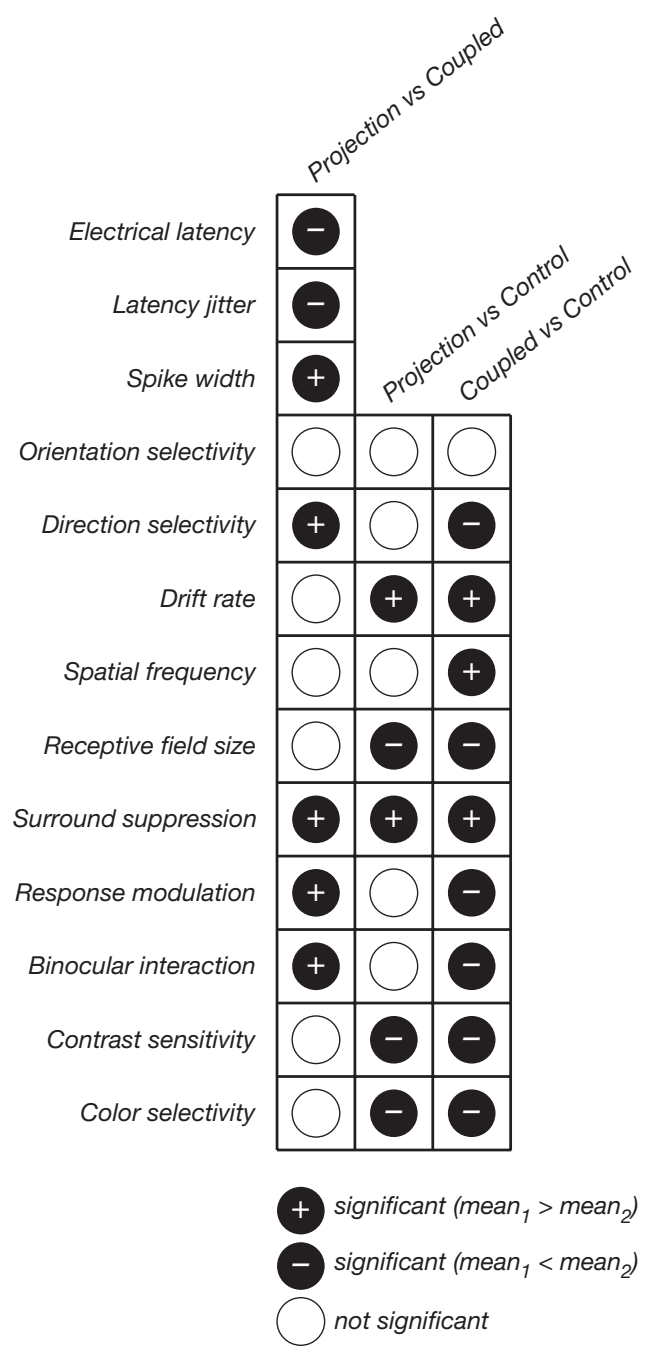

Figure 9. Summary of comparisons between the properties of projection, coupled, and control neurons. In this schematic representation of the statistical tests in Table 1, different response properties are evaluated in each row, and different neuronal subsets are compared in each column. Filled circles indicate a statistically significant difference between the means of the comparison distributions (permutation analyses, $p \leq 0.025$ ): cases where the mean of the first comparison group was greater (black plus sign), cases where that mean was smaller (black minus sign), and cases where the differences were not significant (white). Projection and coupled neurons could be distinguished based on all three electrical properties (latency, jitter, and spike width); these neurons were significantly different with respect to four visual response properties: direction selectivity, surround suppression, binocular interaction, and response modulation. Stronger surround suppression was the only property that distinguished projection neurons from both coupled and control neurons.

two areas (Livingstone and Hubel, 1987; Sincich and Horton, 2002, 2005). We wondered how much of the diversity of our projection neurons was due to combining data obtained from stimulating and recording all functional compartments. Unfortunately, the antidromic stimulation technique is not well suited to answer this question; the method has limited spatial precision, because current spreads around the stimulating electrodes. So even if we knew the location of stimulation sites, we could not be confident that effective stimulating current did not spread across multiple compartments. We therefore made no attempt to relate our results to patterns of CO staining. It may become possible to reveal more specificity and order with more refined methods than those available to us today, such as optogenetic control of spatially targeted neuronal populations (Petreanu et al., 2007; Kaneda et al., 2011; Tye et al., 2011). 
Our results provide a foundation for future studies of how V1 inputs shape the structure of $\mathrm{V} 2$ receptive fields. They allow us to design visual stimuli that best drive striate inputs to V2, and we have begun using this approach (B. Vintch, personal communication). Our findings also highlight an important distinction between two major feedforward projections from striate to extrastriate cortex, one that is functionally specific (the MT projection, see Movshon and Newsome, 1996) and one that is functionally general (the V2 projection studied here). That V2 appears to receive inputs from all main functional types of $\mathrm{V} 1$ neurons may explain why it has been challenging to uncover the hallmark computations that uniquely distinguish V2 from V1.

\section{References}

Anzai A, Peng X, Van Essen DC (2007) Neurons in monkey visual area V2 encode combinations of orientations. Nat Neurosci 10:1313-1321. CrossRef Medline

Bishop PO, Burke W, Davis R (1962) Single-unit recording from antidromically activated optic radiation neurones. J Physiol 162:432-450. Medline

Boynton GM, Hegdé J (2004) Visual cortex: the continuing puzzle of area V2. Curr Biol 14:R523-R524. CrossRef Medline

Bredfeldt CE, Cumming BG (2006) A simple account of cyclopean edge responses in macaque V2. J Neurosci 26:7581-7596. CrossRef Medline

Brincat SL, Connor CE (2004) Underlying principles of visual shape selectivity in posterior inferotemporal cortex. Nat Neurosci 7:880-886. CrossRef Medline

Bullier J, Kennedy H (1983) Projection of the lateral geniculate nucleus onto cortical area V2 in the macaque monkey. Exp Brain Res 53:168-172. Medline

Cavanaugh JR, Bair W, Movshon JA (2002) Nature and interaction of signals from the receptive field center and surround in macaque V1 neurons. J Neurophysiol 88:2530-2546. CrossRef Medline

Curcio CA, Harting JK (1978) Organization of pulvinar afferents to area 18 in the squirrel monkey: evidence for stripes. Brain Res 143:155-161. CrossRef Medline

Derrington AM, Krauskopf J, Lennie P (1984) Chromatic mechanisms in lateral geniculate nucleus of macaque. J Physiol 357:241-265. Medline

Dhruv NT, Tailby C, Sokol SH, Lennie P (2011) Multiple adaptable mechanisms early in the primate visual pathway. J Neurosci 31:15016-15025. CrossRef Medline

El-Shamayleh Y, Movshon JA (2011) Neuronal responses to texturedefined form in macaque visual area V2. J Neurosci 31:8543-8555. CrossRef Medline

Ferrera VP, Nealey TA, Maunsell JH (1994) Responses in macaque visual area V4 following inactivation of the parvocellular and magnocellular LGN pathways. J Neurosci 14:2080-2088. Medline

Gallant JL, Braun J, Van Essen DC (1993) Selectivity for polar, hyperbolic, and Cartesian gratings in macaque visual cortex. Science 259:100-103. CrossRef Medline

Girard P, Bullier J (1989) Visual activity in area V2 during reversible inactivation of area 17 in the macaque monkey. J Neurophysiol 62:1287-1302. Medline

Girard P, Hupé JM, Bullier J (2001) Feedforward and feedback connections between areas V1 and V2 of the monkey have similar rapid conduction velocities. J Neurophysiol 85:1328-1331. Medline

Hegdé J, Van Essen DC (2000) Selectivity for complex shapes in primate visual area V2. J Neurosci 20:RC61. Medline

Hegdé J, Van Essen DC (2003) Strategies of shape representation in macaque visual area V2. Vis Neurosci 20:313-328. Medline

Hubel DH, Wiesel TN (1970) Stereoscopic vision in macaque monkey. Cells sensitive to binocular depth in area 18 of the macaque monkey cortex. Nature 225:41-42. CrossRef Medline

Hussar CR, Pasternak T (2009) Flexibility of sensory representations in prefrontal cortex depends on cell type. Neuron 64:730-743. CrossRef Medline

Ito M, Komatsu H (2004) Representation of angles embedded within contour stimuli in area V2 of macaque monkeys. J Neurosci 24:3313-3324. CrossRef Medline

Kaneda K, Kasahara H, Matsui R, Katoh T, Mizukami H, Ozawa K, Watanabe D, Isa T (2011) Selective optical control of synaptic transmission in the subcortical visual pathway by activation of viral vector-expressed halorhodopsin. PLoS One 6: e18452. CrossRef Medline

Lennie P, Krauskopf J, Sclar G (1990) Chromatic mechanisms in striate cortex of macaque. J Neurosci 10:649-669. Medline

Livingstone MS, Hubel DH (1984) Anatomy and physiology of a color system in the primate visual cortex. J Neurosci 4:309-356. Medline

Livingstone MS, Hubel DH (1987) Connections between layer 4B of area 17 and the thick cytochrome oxidase stripes of area 18 in the squirrel monkey. J Neurosci 7:3371-3377. Medline

Lund JS, Hendrickson AE, Ogren MP, Tobin EA (1981) Anatomical organization of primate visual cortex area VII. J Comp Neurol 202:19-45. CrossRef Medline

Marcus DS, Van Essen DC (2002) Scene segmentation and attention in primate cortical areas V1 and V2. J Neurophysiol 88:2648-2658. CrossRef Medline

Maunsell JH, Nealey TA, DePriest DD (1990) Magnocellular and parvocellular contributions to responses in the middle temporal visual area (MT) of the macaque monkey. J Neurosci 10:3323-3334. Medline

McCormick DA, Connors BW, Lighthall JW, Prince DA (1985) Comparative electrophysiology of pyramidal and sparsely spiny stellate neurons of the neocortex. J Neurophysiol 54:782-806. Medline

Merrill EG, Ainsworth A (1972) Glass-coated platinum-plated tungsten microelectrodes. Med Biol Eng 10:662-672. CrossRef Medline

Mitchell JF, Sundberg KA, Reynolds JH (2007) Differential attentiondependent response modulation across cell classes in macaque visual area V4. Neuron 55:131-141. CrossRef Medline

Movshon JA, Newsome WT (1996) Visual response properties of striate cortical neurons projecting to area MT in macaque monkeys. J Neurosci 16:7733-7741. Medline

Movshon JA, Thompson ID, Tolhurst DJ (1978a) Spatial summation in the receptive fields of simple cells in the cat's striate cortex. J Physiol 283:5377. Medline

Movshon JA, Thompson ID, Tolhurst DJ (1978b) Receptive field organization of complex cells in the cat's striate cortex. J Physiol 283:79-99. Medline

Nassi JJ, Callaway EM (2007) Specialized circuits from primary visual cortex to V2 and area MT. Neuron 55:799-808. CrossRef Medline

Ohzawa I, Freeman RD (1986) The binocular organization of simple cells in the cat's visual cortex. J Neurophysiol 56:221-242. Medline

Pasupathy A, Connor CE (2001) Shape representation in area V4: positionspecific tuning for boundary conformation. J Neurophysiol 86:25052519. Medline

Peirce JW, Solomon SG, Forte JD, Lennie P (2008) Cortical representation of color is binocular. J Vis 8:1-10. CrossRef Medline

Peterhans E, von der Heydt R (1989) Mechanisms of contour perception in monkey visual cortex. II. Contours bridging gaps. J Neurosci 9:1749_ 1763. Medline

Petreanu L, Huber D, Sobczyk A, Svoboda K (2007) Channelrhodopsin-2assisted circuit mapping of long-range callosal projections. Nat Neurosci 10:663-668. CrossRef Medline

Qiu FT, von der Heydt R (2005) Figure and ground in the visual cortex: v2 combines stereoscopic cues with gestalt rules. Neuron 47:115-166. Medline

Ringach DL, Hawken MJ, Shapley R (1997) Dynamics of orientation tuning in macaque primary visual cortex. Nature 387:281-284. CrossRef Medline

Rockland KS (1992) Laminar distribution of neurons projecting from area V1 to V2 in macaque and squirrel monkeys. Cereb Cortex 2:38-47. CrossRef Medline

Roe AW, Ts'o DY (1995) Visual topography in primate V2: multiple representation across functional stripes. J Neurosci 15:3689-3715. Medline

Schiller PH, Malpeli JG (1977) The effect of striate cortex cooling on area 18 cells in the monkey. Brain Res 126:366-369. CrossRef Medline

Sincich LC, Horton JC (2002) Divided by cytochrome oxidase: a map of the projections from V1 to V2 in macaques. Science 295:1734-1737. CrossRef Medline

Sincich LC, Horton JC (2005) The circuitry of V1 and V2: integration of color, form, and motion. Annu Rev Neurosci 28:303-326. CrossRef Medline

Skottun BC, De Valois RL, Grosof DH, Movshon JA, Albrecht DG, Bonds AB (1991) Classifying simple and complex cells on the basis of response modulation. Vision Res 31:1078-1086. CrossRef 
Smith MA, Bair W, Movshon JA (2002) Signals in macaque striate cortical neurons that support the perception of glass patterns. J Neurosci 22: 8334-8345. Medline

Solomon SG, Lennie P (2005) Chromatic gain controls in visual cortical neurons. J Neurosci 25:4779-4792. CrossRef Medline

Tailby C, Solomon SG, Dhruv NT, Lennie P (2008) Habituation reveals fundamental chromatic mechanisms in striate cortex of macaque. J Neurosci 28:1131-1139. CrossRef Medline

Tanabe S, Cumming BG (2008) Mechanisms underlying the transformation of disparity signals from V1 to V2 in the macaque. J Neurosci 2008: 44. Medline

Thomas OM, Cumming BG, Parker AJ (2002) A specialization for relative disparity in V2. Nat Neurosci 5:472-478. CrossRef Medline

Tye KM, Prakash R, Kim SY, Fenno LE, Grosenick L, Zarabi H, Thompson KR, Gradinaru V, Ramakrishnan C, Deisseroth K (2011) Amygdala circuitry mediating reversible and bidirectional control of anxiety. Nature 471:358-362. CrossRef Medline

Tyler CJ, Dunlop SA, Lund RD, Harman AM, Dann JF, Beazley LD, Lund JS (1998) Anatomical comparison of the macaque and marsupial visual cortex: common features that may reflect retention of essential cortical elements. J Comp Neurol 400:449-468. CrossRef Medline

Van Essen DC, Newsome WT, Maunsell JH, Bixby JL (1986) The projec- tions from striate cortex (V1) to areas V2 and V3 in the macaque monkey: asymmetries, areal boundaries, and patchy connections. J Comp Neurol 244:451-480. CrossRef Medline

Vigneswaran G, Kraskov A, Lemon RN (2011) Large identified pyramidal cells in macaque motor and premotor cortex exhibit "thin spikes": implications for cell type classification. J Neurosci 31:14235-14242. CrossRef Medline

von der Heydt R, Zhou H, Friedman HS (2000) Representation of stereoscopic edges in monkey visual cortex. Vision Res 40:1955-1967. CrossRef Medline

Willmore BD, Prenger RJ, Gallant JL (2010) Neural representation of natural images in visual area V2. J Neurosci 30:2102-2114. CrossRef Medline

Yamane Y, Carlson ET, Bowman KC, Wang Z, Connor CE (2008) A neural code for three-dimensional object shape in macaque inferotemporal cortex. Nat Neurosci 11:1352-1360. CrossRef Medline

Yukie M, Iwai E (1985) Laminar origin of direct projection from cortex area V1 to V4 in the rhesus monkey. Brain Res 346:383-386. CrossRef Medline

Zeki SM (1978) The cortical projections of foveal striate cortex in the rhesus monkey. J Physiol 277:227-244. Medline

Zhou H, Friedman HS, von der Heydt R (2000) Coding of border ownership in monkey visual cortex. J Neurosci 20:6594-6611. Medline 